\title{
Ambulatory cleft lip surgery: A value analysis
}

\author{
Jugpal S Arneja MD MBA FRCSC ${ }^{1}$, Craig Mitton PhD²
}

JS Arneja, C Mitton. Ambulatory cleft lip surgery: A value analysis. Can J Plast Surg 2013;21(4):213216.

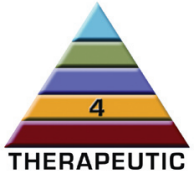

BACKGROUND: Socialized health systems face fiscal constraints due to a limited supply of resources and few reliable ways to control patient demand. Some form of prioritization must occur as to what services to offer and which programs to fund. A data-driven approach to decision making that incorporates outcomes, including safety and quality, in the setting of fiscal prudence is required. A value model championed by Michael Porter encompasses these parameters, in which value is defined as outcomes divided by cost.

OBJECTIVES: To assess ambulatory cleft lip surgery from a quality and safety perspective, and to assess the costs associated with ambulatory cleft lip surgery in North America. Conclusions will be drawn as to how the overall value of cleft lip surgery may be enhanced.

METHODS: A value analysis of published articles related to ambulatory cleft lip repair over the past 30 years was performed to determine what percentage of patients would be candidates for ambulatory cleft lip repair from a quality and safety perspective. An economic model was constructed based on costs associated with the inpatient stay related to cleft lip repair. RESULTS: On analysis of the published reports in the literature, a minority $(28 \%)$ of patients are currently discharged in an ambulatory fashion following cleft lip repair. Further analysis suggests that $88.9 \%$ of patients would be safe candidates for same-day discharge. From an economic perspective, the mean cost per patient for the overnight admission component of ambulatory cleft surgery to the health care system in the United States was USD $\$ 2,390$ and $\$ 1,800$ in Canada.

CONCLUSIONS: The present analysis reviewed germane publications over a 30-year period, ultimately suggesting that ambulatory cleft lip surgery results in preservation of quality and safety metrics for most patients. The financial model illustrates a potential cost saving through the adoption of such a practice change. For appropriately selected patients, ambulatory cleft surgery enhances overall health care value.

Key Words: Ambulatory surgery; Cleft lip; Health care value

$\mathrm{H}$ ealth systems around the world face fiscal constraints in that there is neither an endless supply of resources nor are there reliable ways to control patient demand. This problem is especially germane to the Canadian socialized medical system. As such, health organizations must undergo some form of prioritization with regard to what services to offer and which new programs to fund (1). An evidenced-based approach to this decision-making process that incorporates patient outcomes, including both safety and quality, in the setting of fiscal prudence is required. Traditionally, and with great ease, health systems and practitioners have been able to 'hang their hat' on outcomes, but have not consistently been able to incorporate an economic analysis into their decision-making process.

The United States (US) leads the world in health care spending, which was $17.9 \%$ of gross domestic product (GDP) in 2011 and is trending toward $20 \%$ of GDP by 2020 (2). Although not as significant in Canada compared with the US, health care spending was estimated to be $11.6 \%$ of GDP in 2012, and remains higher compared with many other developed countries (3). Central to the debate on health care

\section{La chirurgie ambulatoire de la fente palatine : une analyse de la valeur}

HISTORIQUE : Les systèmes de santé socialisés sont aux prises avec des
contraintes économiques liées à un approvisionnement limité des res-
sources et à un nombre limité de moyens fiables de contrôler la demande
des patients. Une certaine forme de priorisation se produit quant aux ser-
vices à offrir et aux programmes à financer. Une approche de prise de déci-
sions fondée sur les données s'impose, qui intègre les issues, y compris la
sécurité et la qualité dans un contexte de prudence économique. Un
modèle de valeur préconisé par Michael Porter englobe ces paramètres, où
la valeur correspond aux issues divisées par le coût. OBJECTIFS : Évaluer la chirurgie ambulatoire de la fente palatine sur le plan de la qualité et de la sécurité, ainsi que les coûts qui y sont associés en Amérique du Nord. Les chercheurs tireront des conclusions sur la manière d'améliorer la valeur globale de la chirurgie de la fièvre palatine.

MÉTHODOLOGIE : Les chercheurs ont exécuté une analyse de la valeur des articles publiés relatifs à la réparation ambulatoire de la fente palatine depuis 30 ans pour déterminer le pourcentage de patients qui seraient candidats à une réparation ambulatoire de la fente palatine selon une perspective de qualité et de sécurité. Les chercheurs ont construit un modèle économique fondé sur les coûts associés à l'hospitalisation du patient attribuable à la réparation de la fente palatine.

RÉSULTATS : À l'analyse des rapports publiés, une minorité de patients (28\%) reçoivent leur congé dans un cadre ambulatoire après une réparation de la fente palatine. Selon une analyse plus approfondie, $88,9 \%$ des patients seraient de bons candidats à une chirurgie d'un jour. Sur le plan économique, le coût moyen par patient d'une opération de la fente palatine dans un cadre ambulatoire coûte 2390 \$US au système de santé américain et $1800 \$ C A N$ au système de santé canadien.

CONCLUSIONS : La présente analyse a permis d'examiner les publications pertinentes sur une période de 30 ans, indiquant finalement que la chirurgie ambulatoire de la fente palatine permet de préserver les mesures de qualité et de sécurité chez la plupart des patients. Selon le modèle financier, on pourrait réaliser des économies grâce à l'adoption d'un tel changement de pratique. Chez des patients bien sélectionnés, la chirurgie ambulatoire du palais améliore la valeur globale des soins.

spending is the return on investment for such a significant expenditure. Traditionally challenging to measure, the standard return on investment metric evaluated in health care outcomes has been life expectancy, whereupon in the US, longevity does not equate with expenditure compared with other developed nations (4). Moreover, in any discussion regarding outcomes, quality and safety are front-andcentre parameters that require careful scrutiny because an increasing number of medical errors and prolonged delays in access to the system produce inferior outcomes. A value model that encompasses these parameters has been championed by Michael Porter whereby the simple equation of value $=$ outcomes divided by cost (5). Overall value is enhanced if cost is reduced and/or outcomes improved.

The purpose of the present study was to review the historical practices of postoperative cleft lip care, analyze the outcomes of ambulatory cleft lip surgery from a quality and safety perspective, and offer an estimation of costs associated with ambulatory cleft lip surgery in both the Canadian and American settings. Conclusions will be drawn as to how the overall value of cleft lip surgery may be enhanced.

${ }^{1}$ Division of Plastic Surgery, British Columbia Children's Hospital and University of British Columbia; ${ }^{2}$ Centre for Healthcare Management, Vancouver, British Columbia

Correspondence: Dr Jugpal S Arneja, British Columbia Children's Hospital, Division of Plastic Surgery, A237 Shaughnessy Building, Box 150, 4480 Oak Street, Vancouver, British Columbia V6H 3V4. Telephone 604-875-2794, fax 604-875-2749,

e-mail jugpal.arneja@ubc.ca 
TABLE 1

Total cost of in-hospital (overnight) admission based on bottom-up microcosting analysis

\begin{tabular}{|c|c|c|c|c|}
\hline Country & $\begin{array}{l}\text { New clefts } \\
\text { per year, n }\end{array}$ & $\begin{array}{c}\text { Safe discharge } \\
(88.9 \%), n\end{array}$ & $\begin{array}{c}\text { Cost per } \\
\text { overnight } \\
\text { admission, }\end{array}$ & $\begin{array}{c}\text { Total cost } \\
\text { of admissions }\end{array}$ \\
\hline United States & 4437 & 3944 & USD $\$ 2,390$ & USD $\$ 9,426,160$ \\
\hline Canada & 409 & 364 & CAD $\$ 1,800$ & CAD $\$ 655,200$ \\
\hline
\end{tabular}

\section{METHODS}

University of British Columbia and Children \& Womens' Health (Vancouver, British Columbia) Research Ethics Board approval was obtained to conduct the present study (\#H13-00807). A value analysis was performed; Porter $(5,6)$ defines health care value as outcomes divided by cost and, therefore, both cost as well as outcome evaluations were performed. From an outcome, as well as quality and safety perspective, a review of published articles related to ambulatory cleft lip repair over the past 30 years was performed to determine what percentage of patients would be candidates for ambulatory cleft lip repair. It was assumed that currently no patients were discharged in an ambulatory fashion. The extrapolation of which patients could safely be discharged formed the basis of the cost metrics.

To determine what costs were associated with ambulatory cleft lip surgery compared with inpatient surgery, a bottom-up microcosting model was constructed based on individual costs associated with a onenight inpatient stay because the overwhelming majority of patients are discharged on postoperative day 1 . The Canadian data analysis was conducted using hospital costing data, and every cost associated with the inpatient stay including human resource, property/plant/ equipment, supply and medication. The American data were based on the published literature.

\section{RESULTS}

Are quality and safety preserved in the setting of ambulatory cleft lip surgery?

Integral to any changes in traditional practices of patient care is a careful scrutiny of outcomes from a quality and safety perspective. Due to a change in inpatient duration of hospital stay through the 1980s, a series of audits regarding the complication rates of short-stay were performed (7-13). These authors suggested no significant complications were found with shorter hospital stays. Several more recent reports regarding true ambulatory surgery (day of surgery admission, and same-day postoperative discharge) have also revealed satisfactory outcomes $(8-10,13)$.

Kim and Rothkopf (9) performed a retrospective review of 24 consecutive patients treated with ambulatory surgery compared with inpatient surgery. They concluded that the practice of ambulatory cleft lip surgery was safe and without complications; in fact, there was minor wound separation found with the repair of two patients in the inpatient group. They acknowledged that potential contraindications to ambulatory surgery included patients with concomitant medical problems, long-distance travel requirements or care for twins.

A two-centre retrospective evaluation involving 155 patients treated with ambulatory compared with inpatient cleft lip repair was conducted by Rosen et al (8). Their results suggested no differences between ambulatory or inpatient cleft lip patients with respect to complication or readmission rates; they concluded that patients with preexisting medical conditions would benefit from admission to monitor for serious complications; however, readmission rates may not decrease with either inpatient or ambulatory surgery given the finding that readmissions were often occurring in a delayed fashion.

A multicentre study analyzing cleft lip repair discharge practices involving 2558 patients over a five-year period was performed by Hopper et al (10) and revealed that $72 \%$ of patients were being managed with an overnight inpatient stay postoperatively. On review of ambulatory outcomes, compared with inpatient stay outcomes, these authors found no significant differences between the groups and concluded that serious postoperative medical complications occurred rarely $(1.1 \%)$, and that readmission to hospital was a rare event (1.88\%). They suggested that there were several considerations requisite in deciding whether to admit a patient postcleft lip repair, with the most significant being the patient's overall pre-existing medical status.

Al-Thunyan et al (13) retrospectively reviewed 122 patients managed in either an ambulatory or inpatient fashion. They found no significant differences between patient groups with regard to intraoperative complications, postoperative complications, return to the emergency department or readmission. They concluded that ambulatory surgery was safe, and that patients with pre-existing cardiac or perioperative/ postoperative respiratory disease should be managed as inpatients.

Financial analysis of ambulatory cleft lip surgery in Canada Given the findings above, indicating that no significant differences were found between inpatient or ambulatory surgery and that a majority of the patient population would benefit from ambulatory cleft lip repair, an analysis follows as to the economic impact of a practice change toward ambulatory care.

An epidemiological study examining oral clefting across Canada (14) estimated the number of children born with either an isolated cleft lip or a cleft lip and palate to be 409 per year from 1989 to 2000, corresponding to a prevalence of one in 893 (not including isolated cleft palate patients). Another epidemiological study performed for the province of British Columbia over a 20-year period from 1985 to 2004 (15) estimated the number of children born with either an isolated cleft lip or a cleft lip and palate to be 57 per year, corresponding to a prevalence of one in 900 (not including isolated cleft palate patients). Assuming approximately 409 patients per year are born with an isolated cleft lip or cleft lip and palate in Canada, and based on data from previous studies (10) that suggest that by only admitting children with comorbidities to hospital $(11.1 \%), 88.9 \%$ of children can be safely discharged from hospital without the risk of readmission. It can be inferred that approximately 364 patients in Canada and 3944 in the US would be candidates for ambulatory cleft lip repair, if it is also assumed that currently no patients are discharged the same day of surgery.

Studies from the US analyzing costs associated with cleft lip surgery have estimated costs associated with the overnight admission component of cleft lip repair to be USD $\$ 740$ (11 [1991] ), USD $\$ 1,152$ (9 [1998]), USD\$5,065 (10 [2004]) and USD\$2,605 (16 [2008]). Based on these published data, an estimate of USD $\$ 2,390$ can be attributed to a one-night stay in hospital in the US. There are no published reports describing costs associated with cleft lip repair in Canada. As such, in collaboration with the British Columbia Children's Hospital, an agency of the Provincial Health Services Authority, a bottom-up microcosting analysis of inpatient costs associated with a one-night admission were calculated. The estimated cost associated with a one-night admission to hospital was $\$ 1,800$ (17).

Assuming no patients are currently discharged on the same day of surgery in Canada, 364 patients with a cleft lip undergoing repair would be candidates for same-day discharge and, with an average cost of $\$ 1,800$ (3944 patients in the US at a cost of USD $\$ 2390$ ) for overnight admission, extrapolation of these data suggest annualized costs attributed to same-day discharge in the Canadian health care system compared with the US of $\$ 655,200$ and USD $\$ 9,426,160$ for children undergoing ambulatory cleft lip repair. Table 1 summarizes these data.

\section{DISCUSSION}

Children born with cleft lip with or with cleft palate can be classified among a broader group of orofacial malformations that affect approximately one in 700 new births, ranking these diagnoses near the highest incidence among congenital conditions (6). Although varying in severity and presentation, these children may require both medical 
and surgical care through to adulthood. Historically, children with cleft lip were managed very carefully in the neonatal period given the potential for feeding challenges and poor weight gain. An informal metric to assess fitness for surgery was the ' $10-10-10$ ' rule: 10 weeks of age, $10 \mathrm{lbs}$ $(4.5 \mathrm{~kg})$ of weight and $10 \mathrm{~g}$ of hemoglobin. Once candidates for surgery, often at three to four months of age, these children were admitted to hospital preoperatively, underwent repair of their cleft lip, and subsequently managed as inpatients for several days postoperatively.

\section{Evolution of ambulatory surgery}

In the 1980s, in an effort to minimize disturbance to a child and their family's routine, and to decrease the risk of nosocomial infection rates and contain costs through the advent of managed care in the US, decreased total stay in hospital for pediatric surgical care emerged (7). To be a candidate for ambulatory cleft lip repair, children must be able to be cared for in the same manner as an outpatient as they would be cared for in hospital (8). These children must meet specific discharge criteria including an uncomplicated recovery from anesthesia, wellcontrolled pain, the ability to tolerate an oral dietary intake in the early postoperative period, in additon to well-educated and motivated parents who are able to care for the child (9). With this change in practice toward day-of-surgery admissions and shorter postoperative stays, the overall duration children were admitted to hospital was dramatically reduced. However, despite a subtle trend toward day-of-surgery discharge or ambulatory surgery for cleft lip repair, the great majority of centres continue to admit children postoperatively (10).

\section{Outcomes: Quality and safety}

Numerous studies allude to the safety of same-day discharge for a significant majority of patients post-cleft lip repair. Of course, infants with cardiac or respiratory/airway comorbidities or children with associated syndromes would benefit from overnight observation. Finally, given Canada's geographical disparity, patients travelling long distances would benefit from a night in hospital or to remain in close proximity to the hospital overnight (ie, a Ronald McDonald House or equivalent).

\section{Cost: Can cost savings be realized?}

The principles of opportunity cost and marginal benefit are central to the discussion of prioritization in a health care setting. The opportunity cost represents the lost benefit from the next best use of the resources (1). For example, if there were a possibility to reduce the need for beds by one service, what program or patient population could use those beds would represent an opportunity cost. The opportunity cost of an inpatient bed is the ability to admit another child after a procedure, accept a child from the emergency department or accept a transfer from an outside hospital. The concept of marginal benefit relates to the benefit gained from adding the next unit of resources for a given program. For example, if one extra bed were to be made available because another child did not need a bed postoperatively, that bed could be given to another postoperative child, permitting their surgery to be performed (1).

One issue that is relevant to the present discussion is whether the $>\$ 600,000$ of 'savings' would actually be realized in the Canadian setting. In the quality improvement literature this is known as 'dark green' dollars (as opposed to 'light green' dollars, which refers to savings on paper but not realizable). The main issue to consider in the scenario above is whether staffing would be impacted to the degree that resources attached to a change in staffing due to lower volume could be harvested. Future directions would be to discuss these findings with hospital and health authority administrators to determine how best to realize, in actuality, the savings associated with the change in practice. Assuming budgets would be maintained and staffing unchanged, what opportunity another available bed provides is the benefit for another child to be admitted postoperatively, thereby 'realizing' another completed case for the surgical service.

\section{Limitations}

Limitations of the present study include its retrospective nature and the labour-intensive bottom-up microcosting exercise for a single Canadian children's hospital. We assume that similar costs would be present for other pediatric hospitals in Canada, although some variation is likely.

\section{CONCLUSIONS}

Health care is a complex enterprise, with multiple independent stakeholders often having misaligned and competing interests. Recently, to focus on overall health care value, proponents have drawn attention to not just global health outcomes, but additionally to the expenditures required to achieve said outcome (5). Although small in comparison with the overall GDP associated with health care, the debate surrounding whether to discharge patients following cleft lip repair is a suitable example of practice change to increase health care value. If an equivalent outcome (with quality and safety of paramount importance and not compromised) can be generated at a decreased cost, per Porter's equation, value is increased.

The present analysis reviewed germane publications over a 30-year period, ultimately suggesting that ambulatory cleft lip surgery results in preservation of quality and safety metrics. The financial model presented illustrates the management of opportunity cost in the high utilization Canadian health care system through a practice change. The concepts of marginal benefit and opportunity cost are key principles that should be applied to Canada's socialized health care system and are directly applicable to this example. Certainly, there may be other conditions that this model could be extrapolated to that are currently managed in a similar fashion due to similar historical precedent alone.

Health care practitioners, administrators, insurers and governments must search for innovative methods to create and/or increase health care value. The mandate for these parties will continue to be to strive for 'next' best practices in the setting of fiscal prudence. It would be both undesirable as well as irresponsible for clinicians to ignore economic realities associated with delivering quality health care (16). Clinicians must act in concert with clinical support and administrative support to maintain and grow clinical excellence amid an increasingly challenging economic environment.

DISCLOSURES: The authors have no financial disclosures or conflicts of interest to declare.

PRESENTATION: This study was presented, in part, at The American Cleft Palate-Craniofacial Surgery Annual Meeting, April 2012, San Jose, California, and The Canadian Society of Plastic Surgeons Annual Meeting, June 2013, Calgary, Alberta.

\section{REFERENCES}

1. Mitton C, Donaldson C. Priority Setting Toolkit: A guide to the use of economics in healthcare decision making. London: BMJ Publishing Group 2004: Chapter 1.

2. OECD Health Data 2013. <www.oecd.org/unitedstates/BriefingNote-USA-2013.pdf $>$ (Accessed October 7, 2013).

3. Canada's health care spending growth slows. $<$ www.cihi.ca/cihi-extportal/internet/en/document/spending+and+health+workforce/ spending/release_30oct12> (Accessed, October 7, 2013).

4. OECD Health Data 2006. How Does the United States Compare. <www.oecd.org/health/health-systems/36960035.pdf. <www.oecd. org/health/health-systems/36960035.pdf.\%20Accessed $\% 20$ Oct\%207> (Accessed October 7, 2013).

5. Porter ME. What is value in health care? N Engl J Med 2010;363:2477-81.

6. Abbott MM, Meara JG. Value-based cleft lip-cleft palate care: A progress report. Plast Reconstr Surg 2010;126:1020-5.

7. Lees VC, Pigott RW. Early postoperative complications in primary cleft lip and palate surgery - how soon may we discharge patients from hospital? Br J Plast Surg 1992;45:232-4. 
8. Rosen H, Barrios LM, Reinisch JF, Macgill K, Meara JG Outpatient cleft lip repair. Plast Reconstr Surg 2003;112:381-7.

9. Kim TH, Rothkopf DM. Ambulatory surgery for cleft lip repair. Ann Plast Surg 1999;42:442-4.

10. Hopper RA, Lewis C, Umbdenstock R, Garrison MM, Starr JR. Discharge practices, readmission, and serious medical complications following primary cleft lip repair in 23 U.S. children's hospitals. Plast Reconstr Surg 2009;123:1553-9.

11. Eaton AC, Marsh JL, Pilgram TK. Does reduced hospital stay affect morbidity and mortality rates following cleft lip and palate repair in infancy? Plast Reconstr Surg 1994;94:911-5.

12. Canady JW, Glowacki R, Thompson SA, Morris HL. Complication outcomes based on preoperative admission and length of stay for primary palatoplasty and cleft lip/palate revision in children aged 1 to 6 years. Ann Plast Surg 1994;33:576-80.
13. Al-Thunyan AM, Aldekhayel SA, Al-Meshal O, Al-Qattan MM. Ambulatory cleft lip repair. Plast Reconstr Surg 2009;124:2048-53.

14. León JA, Rouleau J, Oral clefting in Canada: A temporal analysis for the period 1989-2000. Public Health Agency of Canada <www.phac-aspc.gc.ca/ccasn-rcsac/ct2005/or-cl-overview-eng.php> (Accessed October 7, 2013).

15. Uh S-H, Caraveo C, Foster LT, Lowry RB. Birth Prevalence of Cleft Lip and Cleft Palate in British Columbia: Between 1985 and 2004. Public Health Agency of Canada <www.phac-aspc.gc.ca/ccasnrcsac/ct2005/or-cl-bc-eng.php> (Accessed October 7, 2013).

16. Abbott MM, Meara JG. A microcosting approach for isolated, unilateral cleft lip care in the first year of life. Plast Reconstr Surg 2011;127:333-9.

17. Department of Finance, British Columbia Children's Hospital, an agency of the Provincial Health Services Authority. 2012. 